\title{
Triple-Tube-Ostomy:
}

\section{A Novel Technique for the Surgical Treatment of latrogenic Duodenal Perforation}

\author{
Nobuaki Fujikuni Kazuaki Tanabe Hideki Yamamoto \\ Takahisa Suzuki Noriaki Tokumoto Hideki Ohdan
}

Department of Surgery, Division of Frontier Medical Science, Graduate School

of Biomedical Sciences, Hiroshima University, Hiroshima, Japan

\section{Key Words}

Duodenal perforation - Endoscopy · Postoperative course

\begin{abstract}
Although duodenal perforation is currently an infrequent complication of medical procedures, its incidence in the future predictably will increase as endoscopic treatment of duodenal neoplasms becomes more frequently used. In some cases, duodenal perforation is difficult to treat even surgically. We report here a novel technique called 'triple-tube-ostomy' for the treatment of iatrogenic duodenal perforation. Since November 2009 , there have been three cases of iatrogenic perforation of the duodenum, due to various causes, which we have treated with our novel technique. The main principles of the technique are biliary diversion, decompression of the duodenum, and early enteral nutrition. All patients who underwent the triple-tube-ostomy procedure had good postoperative courses, with few complications. The novel surgical technique we describe in this report is safe, reliable, easy to learn and perform, and led to a good postoperative course in all cases where we performed it.
\end{abstract}

\section{Introduction}

Recently, gastroduodenoscopy has identified duodenal neoplasms with increasing frequency. The efficacy of endoscopic mucosal resection (EMR) for the treatment of premalignant lesions of the duodenum, as well as early malignant lesions of the esophagus, stomach, colon, and rectum, is comparable to more classical procedures that have been used. Consequently, the number of EMRs of duodenal neoplasms is increasing. It is expected that the frequency of duodenal perforations inevitably will increase, although some authors reported that no duodenal perforation ever occurred 
during EMR [1]. Some gastrointestinal organs may have a higher risk of EMR-associated perforation; for example, the thinner wall of the duodenum, relative to that of the stomach, would reflect a risk factor.

Traditionally, duodenal perforations have been managed surgically. Some authors advocate a nonsurgical approach (observation and administration of antibiotics) in selected cases of uncomplicated small perforations [2-4]; however, this approach has a high failure rate, and it carries a significant risk of morbidity and mortality [2]. The usefulness of endoclipping has been reported, but its application is limited to relatively small perforations [5]. Even if an appropriate surgical approach is undertaken, it may nonetheless lead to a variety of complications $[2,6]$. Therefore, we must choose the optimal procedure for the particular circumstances.

A similar quandary may need to be taken into account in patients suffering from duodenal ulcer perforation, which is a common cause of peritonitis and requires prompt surgical intervention. Once a duodenal perforation has occurred, the digestive enzymes and bile contained in the organ will leak out and damage the surrounding organs. Most duodenal ulcer perforations are $0.5-1.0 \mathrm{~cm}$ in size; perforations $>2 \mathrm{~cm}$ have been termed giant duodenal ulcer perforations. In an emergency setting, the classic pedicled omental patch repair, described by Cellan-Jones, remains the gold standard of treatment [7]. Postsurgical leakage is a well-known complication after closure of giant duodenal ulcer perforation by using conventional techniques [8].

Our institution is a center for endoscopic therapy, and more than 200 cases of duodenal neoplasms have been treated by endoscopic therapy in the history of our institution. In 4 of these cases, duodenal perforations occurred. In November 2009, we began using a novel technique to treat these perforations, following endoscopic therapy. Three patients with iatrogenic perforation of the duodenum have been treated by this technique called 'triple-tube-ostomy', and the outcome of these procedures is the subject of this study.

\section{Methods}

Patients

Between November 2009 and March 2011, 3 patients with iatrogenic duodenal perforation were included in this study. Perforations occurred in the 3 cases after EMR. All 3 patients were treated surgically with triple-tube-ostomy technique (see below). In all patients, bowel perforation was diagnosed by standard hematological and radiological methods, confirming evidence of pneumoperitoneum. All subjects gave their informed consent to be included in this study, and the study protocol was approved by the institute's committee on human research.

\section{Triple-Tube-Ostomy Technique}

The first step in laparotomy is kocherization of the duodenum, in order to observe the perforated site carefully and to decrease any tension at the repair site. After adequately mobilizing the duodenum, the next step is the closure of the duodenal perforated site by suturing with 1-2 layers. In the setting of chronic inflammation, we add the patch using omentum or intestinal serosa. Following repair of the perforated site, we add a biliary drainage by carrying out cholecystectomy, followed by insertion of a C-tube ( $6 \mathrm{Fr}$ ) into the common bile duct through the cystic duct. The next step is identification of the jejunum 5-15 cm distal to the Treitz ligament, and passage of a 4-mm tube through an antimesenteric enterotomy in a retrograde manner into the junction of the second and third portion of the duodenum. The tubing into the duodenum allows it to be decompressed. In the final step, as a feeding jejunostomy, a 10-Fr catheter is passed into the jejunum through an 
enterotomy in an antegrade manner. This $10-\mathrm{Fr}$ catheter enables early enteral nutrition. After a thorough lavage of the entire peritoneal cavity, drains are placed at appropriate sites.

\section{Case Reports}

Representatively, we show a typical case. Case 3, a 75-year-old woman with duodenal adenoma, underwent EMR. During the procedure, a duodenal perforation occurred which could not be repaired by clipping (fig. 1). X-ray computed tomography indicated a pneumoretroperitoneum, and surgery was immediately performed. The perforated site was in the anal side of the papilla of Vater at the posterior wall (fig. 2). We closed the hole by simple closure without a patch. Cholecystectomy and biliary drainage with a C-tube were performed. To decompress the duodenum, we inserted the decompression tube into the duodenum in a retrograde fashion. As the last step, we performed an enterostomy. The postoperative course was good. Enteral nutrition was started 2 days after the operation, and the patient resumed a scheduled diet on day 18. The retrograde duodenostomy was clamped on day 23 , and the C-tube was clamped on day 25 . The patient was discharged on day 33 , and no complications were observed.

The key clinical findings of all the cases are summarized in table 1. Complications such as perforation or infection did not occur. There was no procedure-related death in any of the three cases studied.

\section{Results}

Details of our new technique, triple-tube-ostomy, are shown in fig. 3 . The three principles of the technique are biliary drainage, decompression of the duodenum with a jejunostomy tube, and enterotomy for early enteral nutrition. The biliary drainage is important, as it inhibits activation of pancreatic enzymes and prevents biochemical damage of the repaired site. Decompression of the duodenum helps to protect the repaired site from mechanical damage.

\section{Discussion}

In the duodenum, especially at the distal side of the papilla of Vater, there are many digestive enzymes (bile, pancreatic juice, and gastric juice). When bile and pancreatic juice mix, the digestive capacity is strengthened. In the case of duodenal perforation, the site of perforation is very important because of the symptomatic differences between the oral and anal sides of the papilla of Vater. If intestinal juice, including bile and pancreatic juice, leaks from the perforated portion, it will damage the surrounding tissues and lead to high-grade edema and inflammation. Delayed treatment may lead to severe complications, including anastomotic leakage, retroperitoneal abscess, and sepsis [9].

Immediate surgery after diagnosis is the current standard for duodenal perforations. However, the standard procedure has not been established. In the case of perforation of bulbs, simple closure seems generally to be acceptable; yet if the perforated portion is at the anal side of the papilla of Vater, care must be taken in selecting the procedure because of the risk of mixing bile and pancreatic juice. Because of autodigestive effects, the possibility of anastomotic leakage will be increased. In these cases, a serosa patch, duo-ileo anastomosis, diverticulization, and pyloric exclusion are customarily performed $[10,11]$. Another surgical procedure, controlled-tube duodenostomy, has 
been described classically for duodenal trauma and is specially designed for large tears in the duodenum [12]. In comparison with many of the alternative procedures, the simplicity of retrograde duodenostomy, feeding jejunostomy, and gastrostomy, especially as emergency procedures, cannot be overemphasized.

All three cases of duodenal perforation that we treated using triple-tube-ostomy showed a very good postoperative course. The patients resumed a scheduled diet within 11-18 days after the operation and were discharged within 23-33 days. We believe that the good postoperative outcome is due to the three simple principles of the technique. In all cases, we added biliary diversion, duodenum decompression for the closure of the perforated point, and enterotomy for early enteral nutrition. The first two principles have been discussed. The third principle, involving a feeding enterotomy, enables early enteral nutrition that may well have a positive effect on immune function and nourishment status. If no abdominal distention occurs, enterotomy feeds may be started within 2-5 days of the operation. Additional factors that contribute to the success of this procedure are proper kocherization of the duodenum (which ensures tension-free repair), good positioning of the biliary drainage tube, and good-sized retrograde duodenostomy that is placed at the junction of the second and third portion of the duodenum. Thus, the procedure relies mainly on keeping the duodenum empty and tension-free by decompressing all of the fluids that either enter in, or are secreted from, the region.

For the biliary diversion step, we insert a C-tube into the common bile duct through the cystic duct. One question that arises is whether that C-tube can fully drain the bile. Although it is commonly thought that the amount of bile produced is almost $1 \mathrm{l} /$ day, the output we observed from the inserted C-tube was only approximately $300 \mathrm{ml} /$ day.

However, the discharge from the duodenostomy was clear. This suggests that during a period of fasting, the bile's productive capacity is decreased, and therefore the C-tube may well be very effective in draining bile.

\section{Disclosure Statement}

The authors have no conflict of interest. 


\begin{tabular}{r|l|l|l}
$\begin{array}{r}\text { Case Reports in } \\
\text { Gastroenterology }\end{array}$ & $\begin{array}{l}\text { Case Rep Gastroenterol 2011;5:672-679 } \\
\text { DOI: 10.1159/000335742 }\end{array}$ & $\begin{array}{l}\text { Published online: } \\
\text { December 30, 2011 }\end{array}$ & $\begin{array}{l}\text { @ 2011 S. Karger AG, Basel } \\
\text { ISSN 1662-0631 } \\
\text { www.karger.com/crg }\end{array}$ \\
\hline
\end{tabular}

Table 1. Three patients with iatrogenic perforation of the duodenum

\begin{tabular}{|c|c|c|c|c|c|c|c|c|}
\hline Case & $\begin{array}{l}\text { Age (years)/ } \\
\text { sex }\end{array}$ & Cause & Location & Size $(\mathrm{mm})$ & $\begin{array}{l}\text { Time to } \\
\text { surgery } \\
\text { (hours) }\end{array}$ & $\begin{array}{l}\text { Compli- } \\
\text { cation }\end{array}$ & $\begin{array}{l}\text { Timing } \\
\text { of oral } \\
\text { intake }\end{array}$ & $\begin{array}{l}\text { Length of } \\
\text { hospital } \\
\text { stay (days) }\end{array}$ \\
\hline 1 & $64 / \mathrm{M}$ & EMR & $3 r d$ & 30 & 152 & - & POD 11 & 28 \\
\hline 2 & $58 / \mathrm{F}$ & EMR & 2nd & 30 & 25 & - & POD 16 & 23 \\
\hline 3 & $75 / \mathrm{F}$ & EMR & $3 r d$ & 25 & 6 & - & POD 18 & 33 \\
\hline
\end{tabular}

EMR = Endoscopic mucosal resection; POD = postoperative day; 2 nd, 3rd = second or third portion of the duodenum.

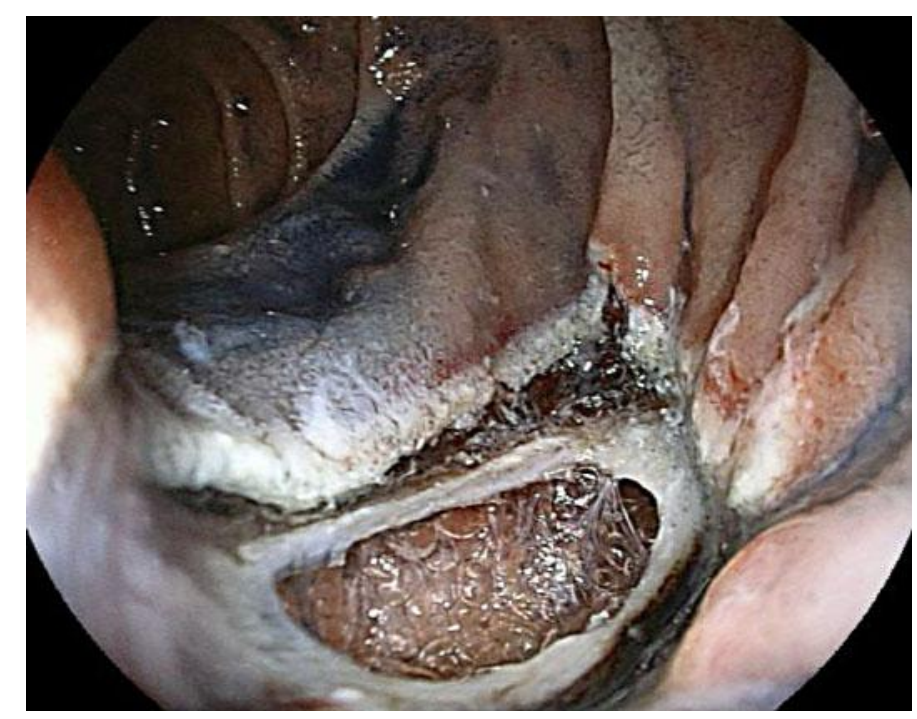

Fig. 1. Endoscopic view after EMR of duodenal adenoma. The perforation was $25 \mathrm{~mm}$ in diameter, and the retroperitoneum space could be seen. 


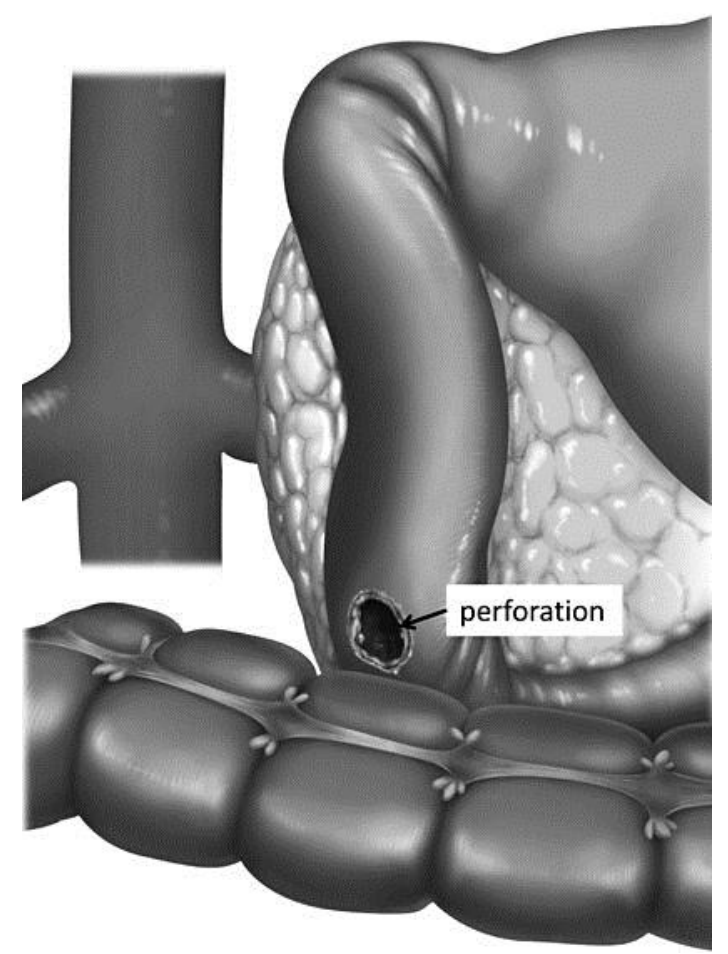

Fig. 2. The perforated site was in the anal side of the papilla of Vater at the posterior wall of the duodenum. 


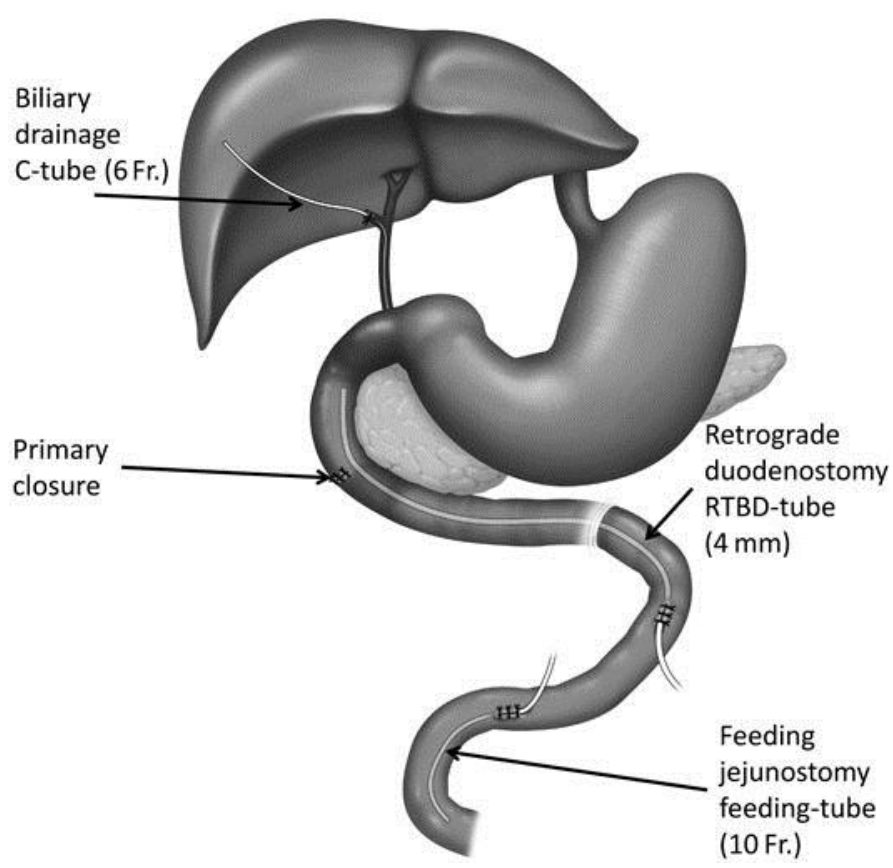

Fig. 3. Schematic line diagram showing placement of the various ostomies along with the steps of the procedure and the order in which they are performed. Step 1: kocherization of the duodenum. Step 2: repair of the perforation. Step 3: cholecystectomy and insertion of the C-tube (6 Fr) into the common bile duct via the cystic duct. Step 4: creation of a retrograde tube duodenostomy. Step 5: creation of a feeding jejunostomy.

\section{References}

$>1$ Sohn JW, Jeon SW, Cho CM, Jung MK, Kim SK, Lee DS, Son HS, Chung IK: Endoscopic resection of duodenal neoplasms: a single-center study. Surg Endosc 2010;24:3195-3200.

-2 Stapfer M, Selby RR, Stain SC, Katkhouda N, Parekh D, Jabbour N, Garry D: Management of duodenal perforation after endoscopic retrograde cholangiopancreatography and sphincterotomy. Ann Surg 2000;232:191-198.

-3 Ames JT, Federle MP, Pealer KM: Perforated duodenal diverticulum: clinical and imaging findings in eight patients. Abdom Imaging 2009;34:135-139.

-4 Lee TH, Bang BW, Jeong JI, Kim HG, Jeong S, Park SM, Lee DH, Park SH, Kim SJ: Primary endoscopic approximation suture under cap-assisted endoscopy of an ERCP-induced duodenal perforation. World J Gastroenterol 2010;16:2305-2310.

5 Charabaty-Pishvaian A, Al-Kawas F: Endoscopic treatment of duodenal perforation using a clipping device: case report and review of the literature. South Med J 2004;97:190-193.

-6 Mathis KL, Farley DR: Operative management of symptomatic duodenal diverticula. Am J Surg 2007;193:305-308; discussion 308-309.

7 Cellan-Jones CJ: A rapid method of treatment in perforated duodenal ulcer. Br Med J 1929;1:1076-1077.

$>8$ Karanjia ND, Shanahan DJ, Knight MJ: Omental patching of a large perforated duodenal ulcer: a new method. Br J Surg 1993;80:65. 
9 Kishimoto H, Kagawa S, Uchida T, Itoh E, Murakami N, Kokudo Y, Muraoka A, Tatsumoto A, Sone Y, Tsumura M, Tsuruno M: Three cases of traumatic duodenal injury. Jpn J Occup Med Traumatol 2000;48:356-360.

10 Kitano M, Yoshii H: Operations for duodenal injuries. Jpn J Acute Med 1997;21:780-788.

11 Kitano M, Sasaki J, Nagashima A, Doi M, Hayashi S, Egawa T, Yoshii H: Operations for pancreatic and duodenal injuries: reconstruction of pancreatic duct and pyloric exclusion. Gastroenterol Surg 2002;25:1557-1565.

12 Asensio JA, Feliciano DV, Britt LD, Kerstein MD: Management of duodenal injuries. Curr Probl Surg 1993;30:1023-1093. 